\title{
Experimental Analysis of Resistive Lubricant Film Thickness with Circular Contact Area
}

\author{
Ritesh Kumar Dewangan*1, Surendra Pal Singh Matharu ${ }^{2}$ \\ ${ }^{1}$ Department of Mechanical Engineering, \\ Rungta College of Engineering \& Technology, Raipur (C.G.) India - 492001 \\ ${ }^{1}$ riteshdewangan12@gmail.com \\ ${ }^{2}$ Department of Mechanical Engineering, \\ National Institute of Technology, Raipur (C.G.) India - 492001 \\ 2spmatharu123@gmail.com
}

\begin{abstract}
Rolling element bearing is one of the most important component of the mechanical machineries. The continuous presence of lubricant between the ball \& races enhances the life of bearing. Online condition monitoring is presently done by vibration signature analysis, ultrasound, acoustic emission \& use of strain gauges. These methods are either complex or costly. A novel online condition monitoring method is used which involves continuous measurement of electrical resistance between the inner and outer race of rolling element bearing, which is indicative of load as well as speed. This resistance is direct measure of lubricants presence between ball and race. A new parameter from this based on Hertz contact theory is defined as Resistive Lubricant Film Thickness (RFT) obtained from experimental analysis of bearing 6307 with lubricant SAE 40.
\end{abstract}

Keyword- Rolling element bearing, Resistive lubricant film thickness (RFT), Resistivity, Bearing resistance.

\section{INTRODUCTION}

Rolling element bearing is a machine component and plays a vital role to transfer the load between the two moving components. Lubricant between the ball and races of the rolling element bearing enhances the life. Lubricant film generated between the ball and races of the bearing depends upon the load and speed of the shaft on which the bearing is mounted. Research on lubricant film thickness with point contact and online condition monitoring of the bearings are done by many researcher. Roy Chowdhury [1] proposed a feed back control system method for online condition monitoring of hydrodynamic journal bearing using film thickness measurement. Number of method to measure the lubricant film thickness have been developed in the past such as interferometry, ultrasound and capacitance method etc.. Prasad [2] have used a theoretical approach to determine the equivalent bearing capacitance, active resistance and impedance of roller bearing on deformation of races and minimum film thickness. Prasad [3] has also observed the effects of operating parameters on the threshold voltages and impedance response of non-insulated rolling element bearings under the influence of varying levels of electrical currents and assessed the film thickness by the measured impedance and current intensity response of the bearings. Prasad [4] reports the cause of generation of localized current in presence of shaft voltage. Also, it bring out the developed theoretical model to determine the value of localized current density depending on dimensional parameters, shaft voltage, contact resistance, frequency of rotation of shaft and rolling-elements of a bearing.

Some researcher has worked on ultrasound methods such as Jie Zhang [5] described a lubricant film monitoring system for a conventional deep groove ball bearing using high frequency ultrasonic transducer mounted in a hole drilled on the static outer raceway of the bearing. The film thickness is calculated using the reflection coefficient characterized by lubricant film. Bruce [6] measured the lubricant-film thickness in a rolling element bearing 6016 using a piezoelectric aluminium nitride thin film transducer. The reflection coefficient from the lubricant layer is then measured from within the lubricated contact and the oil-film thickness extracted via a quasi static spring model. An another method Colorimetric interferomentry were applied by I. Krupa et.al. [7] to the study of EHD lubrication of point contacts under pure rolling conditions to obtain lubricant film shapes. The experimental results for pure rolling conditions were compared with data obtained from numerical isothermal solution. Central and minimum film thickness values were obtained by I. Krupa et.al. [8] using the colorimetric interferometry. And it was observed film thickness decreases as the rolling speed increases. Further the computer-based analysis of interferograms is done to extract the absolute oil-film thickness by O Marklund et.al. [9]. Ioan Ungureanu et. al. [10] also used interferometry to measure the film thickness with point contact and proposed a numerical program to obtain the film thickness distribution from the interferograms. 
The numerical simulation of a steel ball on glass disc contact was performed by Jiaxin Zhao [11] and the results were compared with the experimental results. And it is reported that the numerical model can be used as a valid tool in studying the start up condition in elastohydrodynamic lubrication under different contact situations with different lubricant properties. A numerical solution of isothermal elastohydrodynamic conjunction for concentrated contact of elastic bodies under the elliptical point contact condition is given by $\mathrm{D}$ Jalali-Vahid [12] and it is reported that the lubricant film thickness decreases with increase in load.

R. S. Dwyer-Joyce et. al.[13] has carried out an investigation to study the reflection of ultrasonic waves from the lubricated contact between a sliding steel ball and a at steel disc when substantial solid contact occurs. He has correlated the liquid film stiffness and Solid contact stiffness with the lubricant film thickness. it is reported that the stiffness increases with increase in load and decreases with increase in film thickness, reflection coefficient and speed. An approach has been investigated by R. S. Dwyer-Joyce [14] in which the response of a lubricant - film to an ultrasonic pulse is used to determine the film thickness and it is reported that the film thickness increases with increase in speed of the bearing.

The method for the measurement of the film thickness and condition monitoring used in the past are expensive so an inexpensive online condition monitoring of the bearing based on Resistance method is developed by Matharu et.al [15-19] and calculated the Resistive Lubricant Film Thickness (RFT). The developed formula for RFT requires the Resistivity of the lubricant and is calculated by Matharu [20]. Archard $\&$ Kirk's formula has been used for calculation of lubricant film thickness by Dewangan et.al [21-22]. Further analytical lubricant film thickness is calculated using the Hertz contact theory and Archard \& Kirk's concept for the bearing 6007, 6207, $6307 \& 6407$ [23]. Electrical resistivity of the lubricant is used for the calculation of Resistive lubricant film thickness (RFT), and is calculated experimentally by Dewangan et.al [24] using the design of experiment. Also analytically elliptical and circular contact area for the bearing 6007, 6207, 6307 \& 6407 has been calculated using the Hertz concept by Dewangan et.al [25]. Resistive lubricant film thickness (RFT) is calculated experimentally by Dewangan et.al [26] for the bearing $6207 \& 6307$ considering the elliptical and circular contact area. Dewangan et.al [27] is also used Artificial Neural Network to calculate the elliptical contact area.

In the present work bearing 6307 \& lubricant SAE 40 is selected for the experimentation. Two parameters Load and speed has been chosen for taking the reading of Voltage drop between the bearing ball and race. Readings of the Voltage drop between the ball and race is taken at the Load of $40 \mathrm{~kg}, 60 \mathrm{~kg}, 80 \mathrm{~kg} \& 100$ $\mathrm{kg}$ and at a speed of $800 \mathrm{rpm}, 1000 \mathrm{rpm}, 1200 \mathrm{rpm} \& 1400 \mathrm{rpm}$.

\section{Definitions}

Bearing Resistance $\left(R_{T}\right)$ - It is the electrical resistance of the lubricant trapped between the ball and races of the bearing.

Resistive Lubricant film thickness (RFT)- It is a indicative lubricant film thickness formed between the heaviest loaded ball and race of the ball bearing.

\section{Methodology}

For a ball bearing, the Resistive lubricant film thickness (RFT) based on Hertz contact theory for circular contact area between ball and races is estimated by Matharu et. al $[15,16]$ is given by:

$$
\left(h_{o}\right)_{T}=\frac{a_{1} a_{2}}{\left(a_{1}+a_{2}\right)} \frac{R_{T}}{\rho}
$$

where,

$$
\begin{aligned}
& R_{T}=R_{I R}+R_{O R}, \quad R_{I R}=\frac{\rho h_{o}}{a_{1}}, R_{O R}=\frac{\rho h_{o}}{a_{2}} \\
& a_{1}=\pi\left(a_{i}\right)^{2} \quad \& \quad a_{2}=\pi\left(a_{o}\right)^{2}
\end{aligned}
$$

where, contact radius $a_{i} \& a_{o}$ is calculated from the formula shown below given by Hertzian elastic contact theory [28-30]

where,

$$
a_{i}=\left[\frac{3 Q R_{i}}{4 E^{\prime}}\right]^{1 / 3} \quad \& \quad a_{o}=\left[\frac{3 Q R_{o}}{4 E^{\prime}}\right]^{1 / 3}
$$

$$
\begin{gathered}
\frac{1}{R_{i}}=\frac{1}{r}+\frac{1}{r_{i}}, \quad \frac{1}{R_{o}}=\frac{1}{r}+\frac{1}{r_{o}}, \\
\frac{1}{E^{\prime}}=\frac{1-v_{2}^{2}}{E_{1}}+\frac{1-v_{2}{ }^{2}}{E_{2}}
\end{gathered}
$$

In Table 1 useful dimensions are given, which has been used for the calculation of circular contact area. 


\subsection{Bearing Resistance}

Bearing Resistance for the determination of RFT is calculated by the formula:

$$
I=\frac{\left(V_{i n}-V\right) \times 1000}{R_{k}} \quad \& \quad R_{T}=\frac{V}{I}
$$

On the basis of above formula, different parameter for circular contact area and RFT has been calculated for the Bearing 6307 and Lubricant SAE 40.

\section{EXPERIMENTAL SETUP}

The experimental setup for measurement of RFT is consists of following components and shown in Fig.1.

1. DC Motor: It provides variable speed to the supporting shaft which carries Test Rolling Element Bearing.

2. Storage Oscilloscope: It measures the voltage drop across the bearing.

3. Variable AC Transformer: It supplies current to DC Motor through rectifier. It gives different speed to Rolling Element Bearing with very fine adjustment.

4. Regulated DC Supply: It supplies DC voltage to electrical circuit.

5. Electrical Circuit: Electrical circuits are provided to connect the points of inner race and outer race. It takes input voltage from DC power supply and gives the variation in voltage drop across the bearing depending on the load applied and speed.

6. Supporting Shaft Assembly: It carries a Test Rolling Element Bearing. An arrangement is provided to support the radial load and also the different size of bearings can be attached.

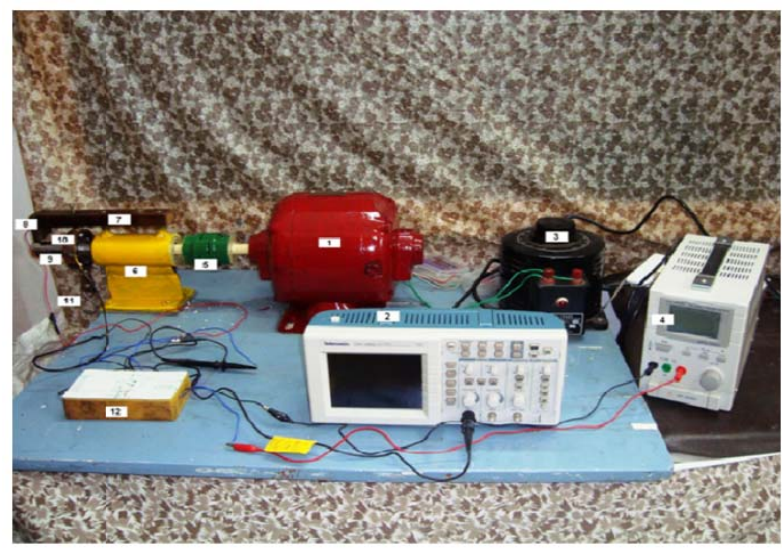

Figure 1: Rolling Element Bearing Test-rig

\section{CAlCulation}

The experimental setup discussed above is operated at $800 \mathrm{rpm}, 1000 \mathrm{rpm}, 1200 \mathrm{rpm} \& 1400 \mathrm{rpm}$ under the load of $40 \mathrm{~kg}, 60 \mathrm{~kg}, 80 \mathrm{~kg} \& 100 \mathrm{~kg}$. The voltage drop across the ball and races of the bearing is recorded under each combination of above speed and load. The reading of Voltage drop is used for the calculation of the Bearing Resistance using Eq. 3 and this is further used to calculate the RFT using the Eq.1.

The Circular contact area used in the Eq. 1 is obtained at different Loads \& Speeds for the bearing 6307 and related Resistive lubricant film thickness is calculated for lubricant SAE 40.

Parameters used for the calculation of circular contact area and Resistive lubricant film thickness is tabulated in the Table 1.

\begin{tabular}{ll} 
Table 1: Parameters for calculation of Circular Contact Area [31] \\
\hline PARAMETERS & BEARING 6307 \\
\hline $\mathrm{D}$ & $13.5 \mathrm{~mm}$ \\
$\mathrm{r}=\mathrm{d} / 2$ & $6.75 \mathrm{~mm}$ \\
$\mathrm{r}_{\mathrm{i}}$ & $22 \mathrm{~mm}$ \\
$\mathrm{r}_{\mathrm{o}}$ & $-35.5 \mathrm{~mm}$ \\
$\mathrm{R}_{\mathrm{i}}$ & $5.17 \mathrm{~mm}$ \\
$\mathrm{R}_{\mathrm{o}}$ & $8.33 \mathrm{~mm}$ \\
$E^{\prime}$ & $113681 \mathrm{~N} / \mathrm{mm}^{2}$ \\
\hline
\end{tabular}


Sample calculations for ball bearing $6307 \&$ Lubricant SAE40 is shown below, remaining are represented graphically.

\subsection{Determination of Circular Contact Area}

Bearing 6307 has been selected for experimentation and the Load on heavily loaded ball can be calculated by Striback's equation

$\mathrm{Q}_{\text {act }}=40 \mathrm{~kg}$

$\mathrm{Q}=0.543 \mathrm{Q}_{\text {act }} \times 9.81=0.543 \times 40 \times 9.81=213.07 \mathrm{~N}$

$\rho=37.65 \times 10^{10} \Omega-\mathrm{mm}$ (from other experiment, not discussed here)

Now the circular contact area shown below is calculated for inner and outer race.

(a) For Inner Race

$$
\begin{aligned}
a_{i}=\left[\frac{3 Q R_{i}}{4 E^{\prime}}\right]^{\frac{1}{3}}= & {\left[\frac{3 \times 213.075 .17}{4 \times 113681}\right]^{\frac{1}{3}} } \\
= & 0.1936 \mathrm{~mm} \\
a_{1}=\pi \times\left(a_{i}\right)^{2} & =\pi \times(0.1936)^{2} \\
& =0.1178 \mathrm{~mm}^{2}
\end{aligned}
$$

\section{(b) For Outer Race}

$$
\begin{aligned}
a_{o}=\left[\frac{3 Q R_{o}}{4 E^{\prime}}\right]^{\frac{1}{3}}= & {\left[\frac{3 \times 213.07 \times 8.33}{4 \times 113681}\right]^{\frac{1}{3}} } \\
= & 0.2271 \mathrm{~mm} \\
a_{1}=\pi \times\left(a_{i}\right)^{2} & =\pi \times(0.2271)^{2} \\
& =0.1621 \mathrm{~mm}^{2}
\end{aligned}
$$

\subsection{Bearing Resistance}

Bearing Resistance for the calculation of RFT is calculated by the given formula:

$$
I=\frac{\left(V_{i n}-V\right) \times 1000}{R_{k}} \quad \& \quad R_{T}=\frac{V}{I}
$$

Reading of Voltage drop across the bearing at $40 \mathrm{~kg} \& 800 \mathrm{rpm}$ is

$V=0.951$ Volt

And, known Voltage \& Resistance are

$V_{\text {in }}=1$ Volt $\quad \& \quad R_{k}=100 \Omega$

Now,

$$
\begin{aligned}
I & =\frac{\left(V_{\text {in }}-V\right) \times 1000}{R_{k}}=\frac{(1-0.952) \times 1000}{100} \\
& =0.49 \times 10^{-6} \mathrm{~A}=0.49 \mu \mathrm{A} \\
R_{T} & =\frac{V}{I}=\frac{0.951}{0.49 \times 10^{-6}}=1940.82 \text { kilo } \Omega
\end{aligned}
$$

Now, Resistive film thickness is calculated by

$$
\begin{aligned}
\left(h_{o}\right)_{T} & =\left[\frac{a_{1} \times a_{2}}{a_{1}+a_{2}}\right] \frac{R_{T}}{\rho} \\
& =\left[\frac{0.1178 \times 0.1621}{0.1178+0.1621}\right] \frac{1940.82 \times 10^{3}}{37.65 \times 10^{10}} \\
& =3.516 \times 10^{-7} \mathrm{~mm}
\end{aligned}
$$

Calculations for remaining readings are also done but not shown here, it is graphically represented in Fig. 2-5.

\section{RESUlts AND Discussion}

An ultrasound method is used by I. Křupka et.al. [8] and reported that the lubricant film thickness increases with the increase in speed. The same result is also observed by R. S. Dwyer-Joyce [14] using the interferometry method. The present experimental setup is based on the resistance method to observe the RFT, and it is calculated for each combination of speed and load selected, and is varying from $0.3516 \mu \mathrm{m}$ to $0.6505 \mu \mathrm{m}$. Obtained results are summarized in Fig. 2-5 where RFT against Load, Speed, Bearing Resistance and Voltage Drop are shown. 
Fig. 2 exhibits the same trend of film thickness as observed by [8,14]. Fig. 3 depicts the results obtained for RFT with increasing velocity. This trend is also observed in numerical solution of D Jalali-Vahid [12]. Fig. 4 shows as Bearing Resistance increase the RFT increases. It is seen from the Eq. 1 that the film thickness is directly proportional to the Bearing Resistance. In this way, result confirms the relation. From Fig. 5 it is observed that as the Voltage increases the RFT increases. It can be seen by Eq. 3, if Voltage drop increases the current owing through the bearing decreases and as the current decreases the Bearing Resistance increases, hence the RFT increases.

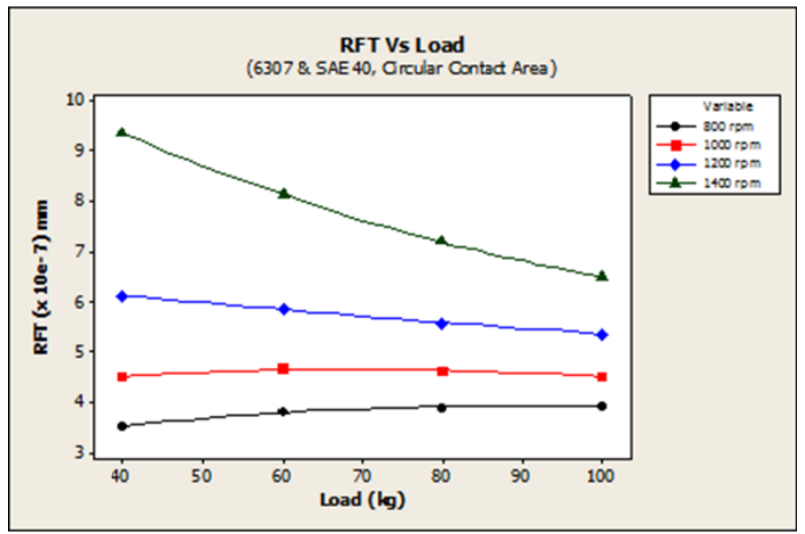

Figure 2: Variation of RFT with Load

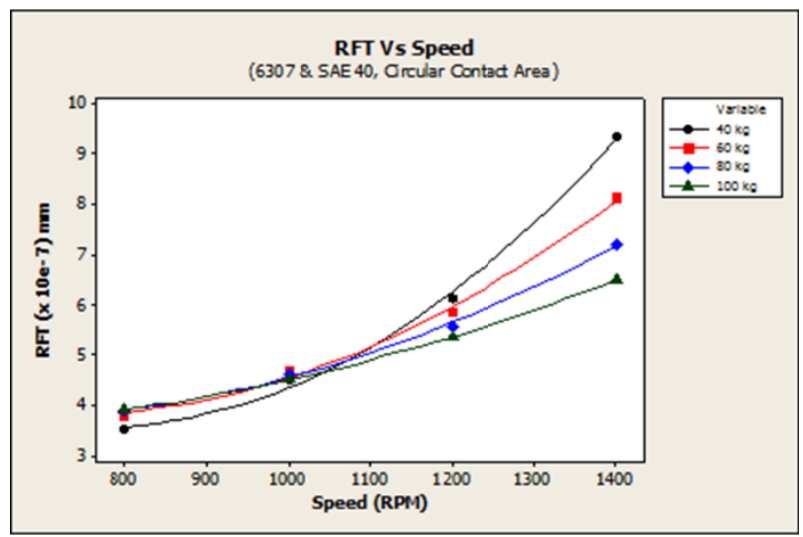

Figure 3: Variation of RFT with Speed

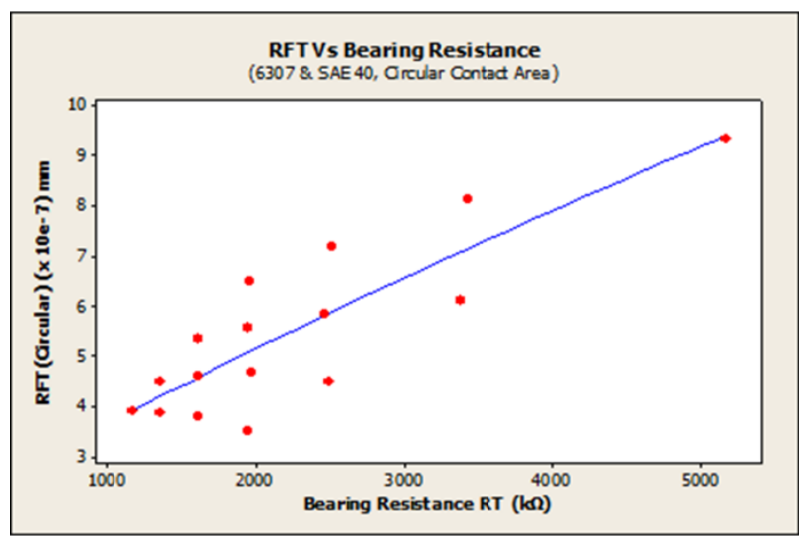

Figure 4: Variation of RFT with Bearing Resistance 


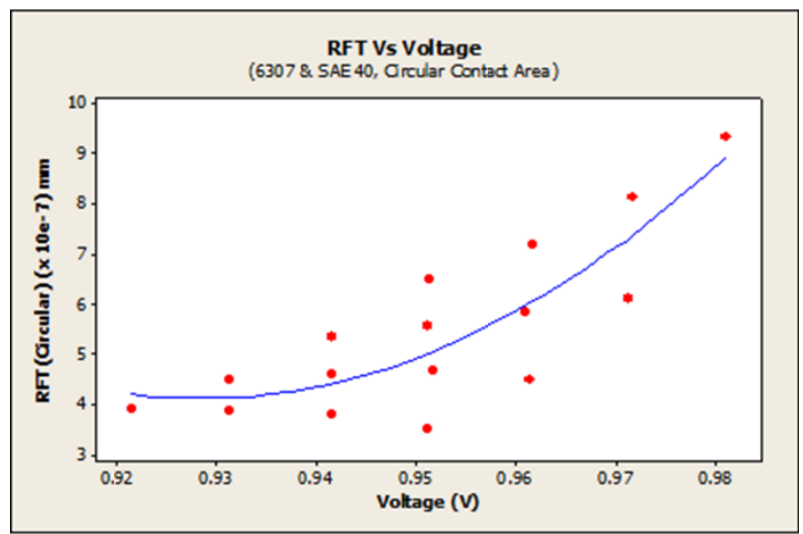

Figure 5: Variation of RFT with Voltage

\section{CONCLUSION}

In the present paper the RFT is computed by resistance method, and the formula derived is based on Hertz contact theory. It is observed that the Resistive film thickness increase with increase in speed, Bearing Resistance \& Voltage and decreases with increase in Load. The result obtained for the lubricant film thickness in the present paper has the good agreement with the results of $[8,12,14]$. The present experimental setup is simple \& inexpensive. Testing of any bearing can be done with ease by minor modification of the setup.

\section{REFERENCES}

[1] Roy Chowdhury S.K. (2000), A feedback control system for plain bearings using film thickness measurement, Tribology International, 33, 29-37.

[2] Prasad Har, Theoretical evaluation of impedance, capacitance and charge accumulation on roller bearing operated under electrical fields, Wear, (1988), 125, 223-239.

[3] Prasad Har, Effect of operating parameters on the threshold voltages and impedance response of non-insulated rolling element bearings under the action of electrical currents, Wear, 117 (1987) $223-240$.

[4] Prasad Har, Diagnosis of Rolling-Element Bearings Failure by Localized Electrical Current Between Track Surfaces of Races and Rolling-Elements, Journal of Tribology - Transactions of the ASME, 2002, 468-473.

[5] Zhang Jie, Drinkwater Bruce W., Dwyer-Joyce Rob S., Monitoring of Lubricant Film Failure in a Ball Bearing Using Ultrasound, Transactions of the ASME, July 2006, Vol. 128, 612-618.

[6] Drinkwater Bruce W., Zhang Jie, Kirk Katherine J., Dwyer-Joyce Jocelyn Elgoyhen Rob S., Ultrasonic Measurement of Rolling Bearing Lubrication Using Piezoelectric Thin Films, Journal of Tribology, January 2009, Vol. 131.

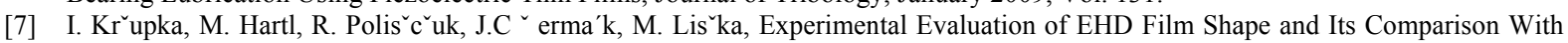
Numerical Solution, Journal of Tribology, October 2000, Vol. 1220, pp. 689-696.

[8] I. Křupka, M. Hartl, M. Liška, Influence of Contact Pressure on Central and Minimum Film Thickness Within Ultrathin Film Lubricated Contacts, Journal of Tribology, October 2005, Vol. 127 / 890-892.

[9] O. Marklund, L. Gustafsson, Interferometry-based measurements of oil-film Thickness, Proc Instn Mech Engrs Part J, Vol 215, pp. 243-259.

[10] Ioan UNGUREANU, Ilie MUSCĂ, Delia Aurora CERLINCĂ, Test Rig for Measurement of Film Thickness in Transient Point Contact Using Interferometry, Mechanical Testing and Diagnosis, 2012 (II), Volume 4, 12-18.

[11] Jiaxin Zhao, Analysis of EHL Circular Contact Start Up: Comparison with Experimental Results, Proceedings of WTC2005, World Tribology Congress III , September 12-16, 2005, Washington, D.C., USA.

[12] D Jalali-Vahid, H Rahnejat and Z M Jin, Elastohydrodynamic solution for concentrated elliptical point contact of machine elements under combined entraining and squeeze-film motion, Proc Instn Mech Engrs Vol 212 Part J 401-411.

[13] R. S. Dwyer-Joyce, T. Reddyhoff, J. Zhu, 2011, "Ultrasonic Measurement for Film Thickness and Solid Contact in Elastohydrodynamic Lubrication", Journal of Tribology, July 2011, Vol. 133.

[14] R. S. Dwye r-Joyce, B. W. Drinkwater, C. J. Donohoe, The measurement of lubricant-film thickness using ultrasound, Proc. R. Soc. Lond. A (2003) 459, 957-976.

[15] Matharu Surendra Pal Singh, Indicative Lubricant Film Thickness For Online Condition Monitoring Of Rolling Element Bearings, International J. of Engg. Research \& Indu. Appls. Vol. 4, No. III (August 2011), pp 1-8

[16] Matharu Surendra Pal Singh, Sanyal Shubhashish, Bal Darshan Singh, Representative Lubricant Film Thickness, a New Concept for Online Condition Monitoring of Rolling Element Bearings, International Journal of Applied Engineering Research, 2011, Volume 6.

[17] Matharu S. P. S., Sanyal S., Bal D. S., Development of a multipurpose, efficient and inexpensive bearing test rig, Journal of Engineering and Technology Research, 2010, Vol. 2(3), pp. 044-049.

[18] Matharu Surendra Pal Singh, Determination of Electrical Resistance of Ball Bearings from Radial Load of Loaded Balls, International Journal of Applied Engineering Research, 2011, Volume 6, Number 11, pp. 1379-1384

[19] Matharu Surendra Pal Singh, Sanyal Shubhashish, Bal Darshan Singh, Determination of Electrical Resistivity of Liquid Lubricants for Online Condition Monitoring of Rolling Element Bearings, International Journal of Applied Engineering Research, 2011, Volume 6, Number 20, pp. 2453-2457.

[20] Matharu S. P. S., Sanyal S., Bal D. S., Development of a Reliable, Inexpensive and Multipurpose Test Rig for Determination of Electrical Resistivity of Liquid Lubricants, International Journal of Pure and Applied Sciences and Technology, 2012.

[21] Dewangan Ritesh Kumar, Matharu Surendra Pal Singh, Evaluation of Archard and Kirk's Lubricant Film Thickness for 6007 Ball Bearing, International Journal of Advances in Engineering Research, Vol. No. 3, Issue No. IV, April 2012, pp. 43-46.

[22] Dewangan Ritesh Kumar, Matharu Surendra Pal Singh, Archard and Kirk's Lubricant Film Thickness for Ball Bearings 6207 and 6307, International Journal of Engineering Studies, Volume 5, Number 1, pp. 7-11. 
[23] Dewangan Ritesh Kumar, Matharu Surendra Pal Singh, Analytical Lubricant Film Thickness For Performance Evaluation of Ball Bearing 6007, 6207, 6307 \& 6407, International Journal of Advances in Engineering \& Technology, Vol. 9, Issue 5, pp. 582-588, October 2016.

[24] Dewangan Ritesh Kumar, Matharu Surendra Pal Singh, Experimental Analysis of Electrical Resistivity of Lubricant for Online Condition Monitoring of Rolling Bearing Using Design of Experiment, Research Journal of Engineering \& Technology, Vol.-7, Issue3, pp-115-120, July-Sept, 2016.

[25] Dewangan Ritesh Kumar, Matharu Surendra Pal Singh, Evaluation and Comparison of Elliptical \& Circular Hertz Contact Area for Bearing 6007, 6207, 6307 \& 6407, International Journal of Engineering Research, Volume No.5, Issue No.12, pp : 911-914, 01.12.2016.

[26] Dewangan Ritesh Kumar, Matharu Surendra Pal Singh, Evaluation of Lubricant Film Thickness for Ball Bearings 6207 \& 6307 with Elliptical \& Circular Contact Area, International Journal of Engineering \& Technology, Volume 9 No1, pp : 208-216, Feb-Mar 2017.

[27] Dewangan Ritesh Kumar, Matharu Surendra Pal Singh, Analysis of Elliptical Contact area of Rolling Element Bearing 6207 using Artificial Neural Network, Indian Journal of Science \& Technology, Vol 10 (5), February 2017.

[28] Harris, T.A., Rolling Bearing Analysis, Fourth Edition, John Wiley \& Sons, Inc., ISBN 0-471-35457-0, 2001.

[29] Hamrock Bernard J., Schmid Steven R., Jacobson BoO., Fundamentals of fluid film lubrication, 2ed, Marcel Dekker, Inc., ISBN: 08247-5371-2, 2004.

[30] Johnson K. L., "Contact Mechanics", Cambridge University Press, 1985.

[31] PSG Design Data Book, 1995, M/s. DPV Printers, Coimbatore.

\section{Nomenclature}

$\begin{array}{ll}Q_{a c t} & \text { - Radial load on bearing }(\mathrm{kg}) \\ Q & \text { - Load on heaviest loaded ball }(\mathrm{N}) \\ a_{i} & \text { - Radius of deformation between inner race and ball }(\mathrm{mm})(\mathrm{mm}) \\ a_{o} & \text { - Radius of deformation between outer race and ball }(\mathrm{mm})(\mathrm{mm}) \\ a_{1} & \text { - Circular Contact Area at inner race }\left(\mathrm{mm}^{2}\right) \\ a_{2} & \text { - Circular Contact Area at outer race }\left(\mathrm{mm}^{2}\right) \\ r & \text { - Radius of ball (mm) } \\ r_{i} & \text { - Outer radius of inner race }(\mathrm{mm}) \\ r_{o} & \text { - Inner radius of outer race }(\mathrm{mm}) \\ R_{i} & \text { - Equivalent radius of ball \& inner race } \\ R_{O} & \text { - Equivalent radius of ball \& outer race } \\ R & \text { - Overall equivalent radius } \\ v_{l}, v_{2} & \text { - Poission's ratio for the material of ball \& race }\left(v_{1}=v_{2}=0.3\right) \\ E^{\prime} & \text { - Equivalent modulus of elasticity }\left(\mathrm{N} / \mathrm{mm}^{2}\right) \\ E_{1}, E_{2} & \text { - Modulus of elasticity for the material of ball } \& \text { race }\left(\mathrm{E}_{1}=\mathrm{E}_{2}=206900 \mathrm{~N} / \mathrm{mm}^{2}\right) \\ R_{T} & \text { - Bearing Resistance (kilo } \Omega) \\ R_{I R} & \text { - Bearing Resistance between ball and inner race }(\Omega) \\ R_{O R} & \text { - Bearing Resistance between ball and outer race }(\Omega) \\ \rho & \text { - Resistivity of lubricant }(\Omega \text {-mm) } \\ \left(h_{o}\right)_{T} & \text { - Resistive film thickness }(\mathrm{RFT})(\mathrm{mm}) \\ V_{i n} & \text { - Input Voltage (Volt) }(\text { Here, it is } 1 \mathrm{Volt}) \\ V & \text { - Voltage drop (Volt) in bearing }(\text { Reading of Oscilloscope }) \\ I & \text { - Current ( } \mu \text { A) } \\ R_{k} & \text { - Known Resistance }(\Omega)(\text { Here, it is } 100 \Omega) \\ & \end{array}$




\section{AUTHOR PROFILE}

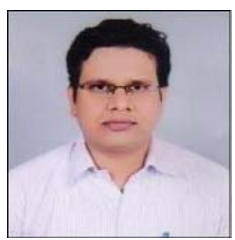

Dr. Ritesh Kumar Dewangan graduated in 2000 from NIT (Earlier GEC), Raipur. He obtained his Master's Degree in 2002 with 'Honours' from MNNIT (Earlier MNREC), Allahabad and Ph.D. in 2017 from N.I.T., Raipur. Presently he is working as Head of Department, Mechanical Engineering in Rungta College of Engineering \& Technology,

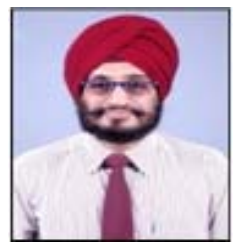

Dr. Surendra Pal Singh Matharu graduated in 1988 form NIT (Earlier GEC), Raipur. He obtained his Master's degree from IIT Kharagpur in 2003 and Ph.D. in 2010 from Pt. Ravishankar Shukla University, Raipur. Presently he is working as Professor, Mechanical Engineering in NIT, Raipur (C.G.) - India. 